\title{
Editorial: transformation
}

\author{
Thomas Gehrig ${ }^{1}$
}

Transformation is the overarching theme of the concluding issue 13(3) of Business Research for at least two reasons: Business Research will be transformed into Schmalenbach Journal of Business Research (SBUR) as of 1, January 2021, and "Digital Transformation" is the topic of the special issue of papers that have been contributed to the Annual Conference 2020 of the Verband der Hochschullehrer für Betriebswirtschaft (VHB, German Academic Association of Business Research) in Frankfurt.

\section{Transformation of Business Research}

This year, the VHB has made the strategic decision to merge its official journal with $S B R$, the official journal of the Schmalenbach Gesellschaft (SG), to form Schmalenbach Journal of Business Research (SBUR). SBUR will be the joint official journal of VHB and SG, and both associations are committed to growing $S B U R$ to a joint flagship journal in business research with global reach and high visibility. SBUR operates under Golden Open Access since the Open Science philosophy will be endorsed by both associations.

Therefore, the present issue concludes the development phase of Business Research as a pioneering open access journal with its volume 13, and it is the last issue of Business Research as you are familiar with it.

Along the traditions of the merged journals, $S B U R$ will continue publishing original high-quality research that is of wide interest to business research and practice. The majority of the Associate Editors will remain in their roles at $S B U R$, providing continuity also in the editorial processes. There will be additional

Thomas Gehrig

thomas.gehrig@univie.ac.at

1 University of Vienna, Vienna, Austria 
Associate Editors to support our main areas of business administration and to cover more specialized research areas and increase global reach. For details, please visit the website of $S B U R$ at https://www.springer.com/journal/41471.

From January 2021 on you will also find links to previous volumes of Business Research on this website.

We are soliciting original research from the full spectrum of business research, but we are also considering review articles and conceptual papers on topical themes. I invite all researchers to submit your best work to $S B U R$ under https://www. editorialmanager.com/sbur/.

\section{Digital transformation}

Due to the accelerating pandemic events in March, this Conference turned out into a real-world exercise of transforming a complete large traditional on-site conference into a fully digital conference within the period of less than 10 days, a most demanding pioneering mission which was orchestrated masterfully by Mark Wahrenburg and his organizing team at the University of Frankfurt.

The Special Issue on "Digital Transformation" focuses on three themes, transformation from humans to artificial intelligence, opportunities of the digital world for management, and particular business transformations currently going on in real time.

The first set of papers discuss the transition from human actors to algorithms and artificial intelligence. Ethical issues are addressed by the two opening papers: one by Alina Köchling und Marius Claus Wehner on "Discriminated by an algorithm: a systematic review of discrimination and fairness by algorithmic decision-making in the context of HR recruitment and HR development", the other one by Paul Hayes on "An Ethical Intuitionist Account of Transparency of Algorithms and its Gradations". Köchling et al. raise awareness about fairness of procedures and ethical conflicts that may arise when employment decisions are delegated to algorithms. While candidate selection will be delegated to a machine and, therefore, be independent of direct personal judgment, potentially serious biases may still arise and remain hidden in the program according to which the machine operates and evaluates. Hayes pushes this position even further from a philosophical perspective by associating transparency as an ethical principle. The author argues that "transparency can be derived as a subsidiary (ethical) principle from other duties including beneficence and justice and that it can be built on the value of knowledge". Essentially, he argues that machines are collections of ethical decisions of humans, and therefore, from an ethical perspective, codes and operations should be made transparent to users.

In their contribution "On the current state of combining human and artificial intelligence for strategic organizational decision making", Anna Trund, Hendrik Birkel and Evi Hartmann also take up this theme of ethical responsibility of humans. While they highlight the vast growth options of human machine interaction in organizational problems, they also argue that because of the greater leverage, ethical 
responsibilities of humans actually need to be increased, and not simply delegated to machines.

This study leads over to the next set of papers, which focuses on opportunities of the process of digital transformation. In their concept paper on "More selforganization, more control-or even both? Inverse transparency as a digital leadership concept", Maren Gierlich-Joas, Thomas Hess und Rahild Neuburger develop a new theory of digital leadership innovation based on the concept of inverse transparency. While digitalization essentially contributes to increasing transparency in organizations, inverse transparency grants a larger say and participation to workers about the use of data within the organization. This concept may contribute to lowering tensions within principal agent relationships and, hence, provides a theoretical basis for further integration of digitalization in leadership research.

Following the dramatic successes of Google and Facebook, fast growing start-up companies, and unicorns in particular, are widely identified with the process of digitalization. "Unicorns-what drives multibillion-dollar valuations?" is the research question that Carolin Bock und Christian Hackober try to resolve. Among many other interesting results, they find that location still matters and may even matter more in a digitalized world, not only because of the presence of sophisticated "quality investors" but also because of network synergies in innovation clusters.

Within a qualitative research design, Wolfgang Becker und Oliver Schmid interview managers on "The right digital strategy for your business: an empirical analysis of the design and implementation of digital strategies in SMEs and LSEs" to identify their digital strategies. While the authors find that not all firms employ a holistic strategy to digitalization, for those that do, significant differences can be assessed for small and medium sized firms (SMEs) relative to larger firms (LSEs).

Finally, the third thematic cluster discusses specific applications of digital transformation for various management activities, revenue management, healthcare, financial services and academic publishing. Claudia Schütze, Catherine Cleophas and Monideepa Tarafdar analyse "Revenue management systems as symbiotic analytics systems: insights from a field study". They show that the organizational structure of processes, e.g., parallel vs. sequential, will affect the nature of communication and analyst training decisively. Their study seems reminiscent of the pioneering work on coarse communication in organizations of Sah and Stiglitz (1986), and essentially translates communication in organizations into the digital world.

The team of Sebastian Hermes, Tobias Riasanov, Eric Clemons, Markus Böhm and Helmut Krcmar investigates "The digital transformation of the healthcare industry: exploring the rise of emerging platform ecosystems and their influence on the role of patients". They identify a number of new functionalities and value drivers in the healthcare industry such as on-demand healthcare, augmented and virtual reality providers, blockchain-based personal health records, cloud service providers, market intermediaries, and intelligent data analysis for healthcare providers. They also analyse how digital innovations affect competition in the health sector and contribute to the changing role of patients. 
Mike Dehnert provides qualitative evidence about "Sustaining the Current or Pursuing the New: Incumbent Digital Transformation in the Financial Services Industry". He finds that it is typically financial service providers that consistently integrate digital services as part of their holistic long-term strategies that are able to create superior performance. Interestingly, these tend to be insurance companies with higher digital process maturity and data capabilities rather than more shortterm oriented financing companies.

The last paper of the Special Issue has also relevance for the strategy of Business Research itself, and therefore, fits nicely to conclude this section as well as the development stage of Business Research. In their study on "Success factors of academic journals in the digital age", Milan Fredrik Klus und Alexander Dilger analyse the adoption of open access strategies and their performance looking at academic journals in the field of management, which includes Business Research as one data point. They find indeed that the availability of open access online services as well as transparent evaluation procedures help journals to increase visibility and enhance citations. Journals that charge APCs for open access perform better than journals charging straight submission fees. The authors recommend that this effect is even enhanced if the publisher is non-commercial. They predict that interim, the market for academic publishing will be a hybrid market with papers available in print and open access but expect that in the long run, the balance will shift towards open access publications.

\section{Concluding remarks}

Finally, let me use the occasion of this concluding volume to thank the editorial team and all persons supporting Business Research. First of all, I would like to thank the Founding Editor Sönke Albers for his vision of starting up an open access journal in management and for his personal engagement in getting the project off the ground. His vision is expanding and generating ample returns. Special thanks go to the Associate Editors for their invaluable support and engagement with Business Research. While most of the Associate Editors will continue at SBUR, I want to thank specifically the Associate Editors, whose terms end with this volume: Marc Fischer and Joachim Gassen. Many thanks go to the Editorial Advisory Boards for supporting Business Research over so many years. Our most important source are our reviewers, whom I thank for their precious time and generous efforts devoted to evaluate submissions and to provide comments and suggestions to authors. Last, but not least, I thank our readership for your interest in Business Research.

We are enthusiastic about the new opportunities that the creation of $S B U R$ generates. Please, continue reading research that will be published in SBUR with curiosity, and submitting high-quality research to $S B U R$. We are looking forward to receiving the very finest of your work under our new flag!

Thomas Gehrig.

Editor-in-Chief. 
Open Access This article is licensed under a Creative Commons Attribution 4.0 International License, which permits use, sharing, adaptation, distribution and reproduction in any medium or format, as long as you give appropriate credit to the original author(s) and the source, provide a link to the Creative Commons licence, and indicate if changes were made. The images or other third party material in this article are included in the article's Creative Commons licence, unless indicated otherwise in a credit line to the material. If material is not included in the article's Creative Commons licence and your intended use is not permitted by statutory regulation or exceeds the permitted use, you will need to obtain permission directly from the copyright holder. To view a copy of this licence, visit http:// creativecommons.org/licenses/by/4.0/.

\section{Reference}

Sah, R.K., and J. Stiglitz. 1986. The architecture of economic systems: hierarchies versus polyarchies. The Am Econ Rev 76 (4): 716-727.

Publisher's Note Springer Nature remains neutral with regard to jurisdictional claims in published maps and institutional affiliations. 